\title{
UM ESTUDO SOBRE AS PUBLICAÇÕES DE INVESTIMENTOS EM MEIO AMBIENTE DO SETOR EMPRESARIAL COM BASE NO BALANÇO SOCIAL
}

Júlio Luiz Cadete da Silva*
José Luis Garcia Hermosilla**
Ethel Cristina Chiari da Silva**
Marcus C. Avezum Alves de Castro**

\section{Resumo:}

Nos últimos anos tem sido freqüente o interesse da sociedade em conhecer os investimentos das empresas em responsabilidade social e meio ambiente. Um desses exemplos pode ser observado ao se conhecer a carta empresarial para o desenvolvimento sustentável da Câmara de Comércio Internacional (CCI), divulgada em 1991, que sugere várias ações que as empresas devem tomar a fim de se prepararem para a nova realidade advinda das questões ambientais. Sendo assim, a preocupação com o meio ambiente, alardeada em todas as esferas da sociedade, deu espaço a dois temas de grande repercussão nos ambientes internos e externos das organizações: a responsabilidade social e a preocupação com o meio ambiente. Nesse contexto, a demonstração que pode fornecer aos stakeholders informações de natureza ambientalé o Balanço Social, que tem por objetivo demonstrar o resultado da interação da empresa com o meio. Diante dessa exposição, a pergunta que se faz é: apesar de todo o empenho da sociedade, pode-se dizer que as empresas vêm gradativamente ampliando seus investimentos relacionados ao meio ambiente? A justificativa desse tema se apóia no fato de as empresas utilizarem as aplicações em meio ambiente e responsabilidade social para fins mercadológicos; entretanto, os valores aplicados e seu verdadeiro comprometimento agregando essas informações às suas demonstrações financeiras só podem ser identificados por ocasião dessas publicações. O objetivo deste trabalho se concentrou em levantar o número de empresas que publicaram informações de natureza social e ambiental, em 2005 e

* Mestre pelo Programa de Mestrado em Desenvolvimento Regional e Meio Ambiente do Centro Universitário de Araraquara - Uniara.

**Professores do Programa de Mestrado em Desenvolvimento Regional e Meio Ambiente do Centro Universitário de Araraquara - Uniara. 
2006, por meio do Balanço Social e, em seguida, verificar o comportamento dos indicadores ambientais divulgados nos referidos balanços e relacionados à produção. O presente trabalho foi desenvolvido por meio de pesquisa descritiva e documental com base nas demonstrações financeiras publicadas em meios específicos. Em resposta à pergunta formulada, analisando o intervalo delimitado na pesquisa, observase que, apesar de existirem modelos minimamente adequados para que as empresas revelem seus verdadeiros interesses em relação ao desenvolvimento sustentável, não se pode dizer que as empresas estão ampliando seus investimentos relacionados à produção visando à sustentabilidade.

Palavras-chave: Meio Ambiente, Responsabilidade Social, Balanço Social.

\section{Introdução}

A sociedade, nos últimos anos, tem apresentado grande interesse em conhecer os investimentos das empresas em responsabilidade social e meio ambiente. Nesse sentido, a carta empresarial para o desenvolvimento sustentável da Câmara de Comércio Internacional (CCI), divulgada em 1991, sugere várias ações que as empresas devem tomar a fim de se prepararem para a nova realidade advinda das questões ambientais. Dentre as várias orientações contidas, destacam-se:

a) Prioridades na empresa: reconhecer a gestão do ambiente como uma prioridade e como fator determinante do desenvolvimento sustentável; estabelecer políticas, programas e procedimentos para conduzir as atividades de modo ambientalmente seguro;

b) Processo de aperfeiçoamento: aperfeiçoar continuamente as políticas, os programas e o desempenho ambiental das empresas, levando em conta os desenvolvimentos técnicos, o conhecimento científico, os requisitos dos consumidores e as expectativas da comunidade, tendo como ponto de partida a regulamentação em vigor, e aplicação dos mesmos critérios ambientais no plano internacional;

c) Formação de pessoas: formar, treinar e motivar as pessoas para desempenhar suas atividades de maneira responsável, face ao ambiente;

d) Instalações e atividades: desenvolver, projetar e operar instalações, tendo em conta a eficiência no consumo da energia e dos materiais; a utilização sustentável dos recursos renováveis; a minimização de impactos ambientais adversos e da produção de rejeitos (resíduos) e o tratamento ou disposição (deposição) final desses resíduos de forma segura e responsável.

Em abril de 2000, o Ministério do Meio Ambiente, por intermédio de sua Secretaria de Políticas para o Desenvolvimento Sustentável, assinou um Termo de Cooperação Técnica com a Associação Brasileira de Normas Técnicas (ABNT), para a

REVISTA UNIARA, $n .^{0}$ 21/22, 2008/2009 implantação do Programa Brasileiro de Rotulagem Ambiental (PBRA), a fim de criar o rótulo ambiental, para identificar os produtos ecologicamente corretos.

As sugestões anteriores representam uma pequena demonstração dos órgãos responsáveis pelas políticas globais em direcionar as empresas no sentido de se preparar para enfrentar as demandas produtivas dentro do conceito de desenvolvimento sustentável. Essa colocação nos remete à reflexão de Camargo (2003, p. 13): "...o termo desenvolvimento sustentável tem evoluído, desde o seu surgimento, de forma a abarcar em si todas as questões que inter-relacionam, meio ambiente e desenvolvimento humano".

Nessa linha se destaca o conceito discutido e divulgado no Relatório de Brundland em 1987, também conhecido como Nosso Futuro Comum. Citando esse documento, Bello (1998, p.25) coloca: "Desenvolvimento sustentável é um processo de transformação, no qual a exploração dos recursos, a direreção dos investimentos, a orientação do desenvolvimento tecnológico e a mudança institucional se harmonizam e reforçam o potencial, presente e futuro, a fim de antender às necessidades e aspirações humanas."

Ressalta-se, portanto, que a preocupação com o meio ambiente, alardeada em todas as esferas da sociedade, deu espaço a dois temas de grande repercussão nos ambientes internos e externos das organizações:

a) Preocupação com o meio ambiente;

b) Responsabilidade Social das empresas.

Quanto à responsabilidade social das empresas cita-se Ashley, Coutinho e Tomei (2000), que apresentam uma análise conceitual e de onde se pode extrair, com relação aos argumentos favoráveis, o seguinte: "Os argumentos, a favor, na linha instrumental consideram que há uma relação positiva entre o comportamento socialmente responsável e a performance econômica da empresa."

Para atender a essa demanda surge um novo ramo da ciência contábil, denominada Contabilidade Ambiental que, segundo Zanluca (2007), pode ser conceituada como: "Contabilidade ambiental é o registro do patrimônio ambiental (bens, direitos e obrigações ambientais) de determinada entidade, e suas respectivas mutações expressos monetariamente. Seu objetivo é propiciar informações regulares aos usuários internos e externos acerca dos eventos ambientais que causaram modificações na situação patrimonial da respectiva entidade, quantificado em moeda."

Para Ribeiro (2005 p.39), "...do ponto de vista da contabilidade, o que se pode medir e fazer constar, nas demonstrações contábeis, são eventos e transações econômico-financeiras, que refletem a interação da empresa com o meio ambiente".

Diante desse desafio, as empresas que se dispuserem a reconhecer os eventos ambientais devem, a priori, adequar o seu plano de contas para essa finalidade.

Um estudo sobre as publicações... 
Outro passo deverá ser dado na correta definição e classificação dos eventos de natureza ambiental, que podem ser descritos resumidamente da seguinte forma:

a) Gastos e custos ambientais - devem ser classificados os gastos com insumos para o aumento ou redução de emissão de gases ou partículas consideradas prejudiciais ao meio ambiente, e as despesas de manutenção com os equipamentos que reduzem a poluição, como, por exemplo, filtros;

b) Ativos ambientais - o termo ativo, em contabilidade, sugere o registro de bens e direitos; sendo assim, os ativos ambientais serão considerados como aqueles bens adquiridos e de propriedade da empresa, destinados a controlar e recuperar o meio ambiente;

c) Passivos ambientais - passivos significam obrigações; nesse sentido, com relação aos passivos ambientais, o processo de definição passa por uma série de dificuldades em sua classificação, uma vez que as empresas que utilizam recursos naturais em seu processo de produção não conseguem, na sua grande maioria, mensurar o impacto da sua atividade no meio ambiente. Deve-se considerar, também, que em algumas atividades, o reconhecimento desse passivo refletiria negativamente em suas demonstrações financeiras. Assim, na grande maioria, os passivos registrados na atualidade se referem a multas por infração às leis ambientais;

d) Despesas de natureza ambiental - as despesas de natureza ambiental são relacionadas à depreciação dos equipamentos e pessoal não envolvido na produção, ligado diretamente aos programas ambientais, entre outros;

e) Receitas ambientais - podem derivar da venda dos produtos recicláveis ou reciclados ou no aproveitamento dos gases para geração de energia alternativa.

Não obstante a necessidade, por parte das empresas, de adequar sua estrutura contábil à nova demanda há vários anos, pode-se encontrar demonstrações que revelam os investimentos ou comprometimentos da empresa com o meio ambiente e, consequentemente, com a sustentabilidade. Dentro dessa ótica se destaca a Demonstração de Valor Adicionado (DVA), que informa o valor da riqueza criada pela empresa e a sua forma de distribuição. Segundo Tinoco (2001), o objetivo principal dessa demonstração é fornecer informações aos diversos grupos participantes nas operações; ainda, segundo o autor, um aspecto importante no cálculo do valor adicionado é a base de mensuração, produção e venda.

A preocupação com o tema e a falta de uma demonstração específica para esse assunto fizeram com que o Conselho Federal de Contabilidade instituísse a Norma Brasileira de Contabilidade (NBC) T n. ${ }^{\circ} 15$, que entrou em vigor a partir de janeiro de 2006, tratando das Informações de Natureza Social e Ambiental, e entre seus itens exige que a empresa informe seus passivos ambientais. Vale salientar que, em quase sua totalidade, ela repete as informações contidas no Balanço Social, tomando-

REVISTA UNIARA, $n .^{0} 21 / 22,2008 / 2009$ se como modelo o sugerido pelo Instituto Brasileiro de Análises Sociais e Econômicas (IBASE). As primeiras divulgações foram feitas em 2007, o que propicia mais uma fonte de dados na busca do trabalho realizado pelas empresas junto ao meio ambiente.

Outra forma de investigar se as empresas estão comprometidas com ações de sustentabilidade ambiental é verificar se as mesmas declaram sua adesão à ISO 14000 (ou suas sub-séries), pois essa norma trata dos Sistemas de Gestão Ambiental; entretanto, esses investimentos ficam no nível interno das organizações.

Nesse contexto, a demonstração que pode fornecer aos usuários externos informações de natureza ambiental é o Balanço Social, que tem por objetivo demonstrar o resultado da interação da empresa com o meio em que está inserida.

Segundo Milani Filho (2008, p. 92): "O Balanço Social nãoé uma peça obrigatória, mas constitui-se num dos principais relatórios sobre as características da empresa e seu relacionamento com diferentes públicos, por isso é considerado relevante para a identificação e avaliação do envolvimento da organização com a Responsabilidade Social."

Ainda com relação ao Balanço Social, Tinoco (2001) revela que: "Mais recentemente, a sociedade, sujeito e objeto das atividades humanas, vem propugnando por maior abertura, quanto à revelação de informações econômicas, financeiras, sociais e ambientais, que justifiquem a razão de ser das entidades, como sujeitos públicos, inserindo-se, portanto, no contexto dos usuários do Balanço Social."

A História do Balanço Social começa nos anos 60, quando, nos Estados Unidos e na Europa, a população decidiu boicotar os produtos das empresas envolvidas em conflitos armamentistas, mais precisamente a Guerra do Vietnã. A exigência de uma postura ética por parte das empresas deu surgimento às primeiras demonstrações de caráter social. No Brasil, o movimento pela publicação das informações sociais ganhou força a partir de 1997, quando o sociólogo Herbert José de Souza, o Betinho, liderou uma ampla campanha pela divulgação do Balanço Social, inclusive sugerindo o modelo que deveria ser adotado, como forma de padronizar as informações.

No Balanço Social modelo IBASE, que foi lançado em 1997 e inspirado no formato dos balanços financeiros, encontra-se um número expressivo de informações relacionadas à responsabilidade social das empresas, que estão divididas em sete grupos, a saber:

(1) Bases de cálculo - Receita Líquida (RL), Resultado Operacional (RO) e Folha de Pagamento Bruta (FPB), em que a Receita Líquida é igual ao total das vendas menos os impostos. O Resultado Operacional corresponde à Receita Líquida 
menos os custos e as despesas operacionais;

(2) Indicadores Sociais Internos - são relacionados itens despendidos em (3) Indicadores Sociais Externos - expõem os valores gastos em cultura, saúde, combate à fome e em segurança alimentar;

(4) Indicadores ambientais - contemplando, precisamente, somente duas linhas, chamadas investimentos relacionados com a produção/operação da empresa, cuja somatória indica que são os totais de investimentos em meio ambiente;

(5) Indicadores do corpo funcional-medem o número de empregados no início e no fim dos períodos, incluindo cargos de chefia do sexo feminino e número de trabalhadores negros, entre outros;

(6) Informações relevantes quanto à cidadania empresarial;

(7) Outras informações

Sendo o Balanço Social o instrumento que revela a interação da empresa com o ambiente em que está inserida, e tomando-se por base o modelo sugerido pelo IBASE, levantaram-se, no item 4 (quatro), indicadores ambientais, dados que podem revelar os investimentos relacionados ao meio ambiente com produção e em programas ou projetos externos, que são apresentados conforme modelo da tabela 1 .

Tabela 1. Balanço Social modelo IBASE - Item 4.

\begin{tabular}{|l|c|c|c|c|c|c|}
\hline \multicolumn{3}{|c|}{ Ano 1 } & Ano 2 \\
\hline 4 - Indicadores Ambientais & $\begin{array}{c}\text { Valor } \\
\text { (mil) }\end{array}$ & $\begin{array}{c}\% \text { sobre } \\
\text { RO }\end{array}$ & $\begin{array}{c}\% \text { sobre } \\
\text { RL }\end{array}$ & $\begin{array}{c}\text { Valor } \\
\text { (mil) }\end{array}$ & $\begin{array}{c}\% \text { sobre } \\
\text { RO }\end{array}$ & $\begin{array}{c}\% \text { sobre } \\
\text { RL }\end{array}$ \\
\hline $\begin{array}{c}4.1 \text { - Investimentos relacionados com a } \\
\text { produção/operação da empresa }\end{array}$ & & & & & & \\
\hline $\begin{array}{c}4.2 \text { - Investimentos em programas e/ou } \\
\text { projetos externos }\end{array}$ & & & & & & \\
\hline $\begin{array}{l}\text { Total dos investimentos em meio } \\
\text { ambiente }\end{array}$ & & & & & \\
\hline
\end{tabular}

Fonte: www.ibase.org.br.

A Demonstração de Valor Agregado (DVA) e o Balanço Social têm sido publicados em jornais econômicos de grande circulação juntamente com as Demonstrações Financeiras das empresas. É fato comum a colocação destes fora do Sistema de Informações Contábeis; sendo assim, elas podem ser encontradas no Relatório da Administração ou em Notas Explicativas, que são denominadas dessa forma por serem complementos às Demonstrações Financeiras. $\mathrm{O}$ fato de essas demonstrações não serem obrigatórias por lei também permite que as empresas decidam se as mesmas devem ou não ser levadas ao conhecimento do público.

REVISTA UNIARA, $n .^{0} 21 / 22,2008 / 2009$
Diante dessa exposição, se questiona: apesar de todo o empenho da sociedade, pode-se dizer que as empresas vêm gradativamente ampliando seus investimentos relacionados ao meio ambiente?

A justificativa desse tema se apóia no fato de as empresas utilizarem as aplicações em meio ambiente e responsabilidade social para fins mercadológicos; entretanto, os valores aplicados e seu verdadeiro comprometimento agregando essas informações às suas demonstrações financeiras só podem ser identificados por ocasião dessas publicações.

O objetivo geral, neste trabalho, se concentrou em levantar qual é o número de empresas que publicaram as informações de natureza social e ambiental, extraindo delas o Balanço Social e verificando o comportamento dos indicadores ambientais.

Como metodologia, foram utilizadas as pesquisas descritiva e documental, com base nas demonstrações financeiras publicadas em veículos específicos, como o jornal "A Gazeta Mercantil", compreendidos dentro dos períodos de março e abril de 2005 e 2006, por ocasião das demonstrações financeiras dos anos 2004 e 2005.

\section{Levantamento das publicações}

Nos períodos escolhidos foram levantadas 76 publicações distribuídas como apresentado na tabela 2 .

Tabela 2. Número de Demonstrações Financeiras publicadas no período.

\begin{tabular}{|c|c|c|c|c|c|c|}
\hline Publicações & $\mathbf{2 0 0 4}$ & $\mathbf{\%}$ & $\mathbf{2 0 0 5}$ & $\mathbf{\%}$ & Total & $\mathbf{\%}$ \\
\hline Demonstrações financeiras (DF) & 46 & 61 & 30 & 39 & 76 & 100 \\
\hline
\end{tabular}

Para efeito da análise, foram distribuídas as demonstrações dentro dos ramos de atividade, conforme a tabela 3 .

Tabela 3. Demonstrações Financeiras (DF) por ramo de atividade.

\begin{tabular}{|l|c|c|c|c|c|c|}
\hline Demonstrações financeiras (DF) & $\mathbf{2 0 0 4}$ & $\mathbf{\%}$ & $\mathbf{2 0 0 5}$ & $\mathbf{\%}$ & Total & \% \\
\hline Industrial & 14 & 30 & 12 & 40 & 26 & 34 \\
\hline Comércio & 03 & 7 & 02 & 7 & 05 & 7 \\
\hline Serviços & 29 & 63 & 16 & 53 & 45 & 59 \\
\hline Total & 46 & 100 & 30 & 100 & 76 & 100 \\
\hline
\end{tabular}

Dos ramos de atividade, segmentou-se por área de atuação e foram extraídos os que apresentaram Balanço Social, segundo os moldes sugeridos pelo IBASE. Esse levantamento é apresentado na Tabela 4.

Um estudo sobre as publicações... 
Tabela 4. Número de empresas que publicaram Balanço Social no período.

\begin{tabular}{|l|c|cc|c|c|c|}
\hline Balanço Social (BS) & $\mathbf{2 0 0 4}$ & $\mathbf{\%}$ & $\mathbf{2 0 0 5}$ & $\mathbf{\%}$ & Total & $\mathbf{\%}$ \\
\hline Industrial & & & & & & \\
\hline Petrolífera \\
$\begin{array}{l}\text { Siderurgia } \\
\text { Comércio }\end{array}$ & 1 & 5,6 & 1 & 7,6 & 2 & 6,5 \\
\hline $\begin{array}{l}\text { Comércio } \\
\begin{array}{l}\text { Serviços } \\
\text { Geração de energia }\end{array}\end{array}$ & 14 & 77,7 & 10 & 77,2 & 24 & 77,5 \\
\hline Total & 18 & 100,0 & 13 & 100,0 & 31 & 100,0 \\
\hline
\end{tabular}

\section{Investimentos relacionados com a produção/operação da empresa}

Para efeito dessa análise, foram extraídos da demonstração os valores investidos relacionados com a produção ou operação da empresa. O fato de a publicação demonstrar o ano anterior permitiu a análise das aplicações realizadas nos últimos três anos para as empresas que estiveram presentes no período delimitado nos dois anos. Esse levantamento é apresentado nas tabelas 5,6 e 7 .

a) Indústrias

Tabela 5. Investimentos relacionados à produção do setor petrolífero.

\begin{tabular}{|c|c|c|c|c|c|c|c|c|c|}
\hline \multicolumn{10}{|c|}{ Atividade: Petrolífera } \\
\hline \multirow[t]{2}{*}{ Empresa } & \multicolumn{3}{|c|}{2003} & \multicolumn{3}{|c|}{2004} & \multicolumn{3}{|c|}{2005} \\
\hline & Valor & $\% \mathrm{RO}$ & \%RL & Valor & $\% \mathrm{RO}$ & \%RL & Valor & $\% \mathrm{RO}$ & $\% \mathrm{RL}$ \\
\hline PETROBRÁS & 2.249 .751 & 8,00 & 2,00 & 1.515 .625 & 6,00 & 1,00 & 1.224 .745 & 3,34 & 0,90 \\
\hline
\end{tabular}

Tabela 6. Investimentos relacionados à produção do setor siderurgia.

\begin{tabular}{|l|r|r|r|r|r|r|r|r|r|r|}
\hline \multicolumn{10}{|c|}{ Atividade: Siderurgia } \\
\hline \multirow{2}{*}{ Empresa } & \multicolumn{3}{|c|}{$\mathbf{2 0 0 3}$} & \multicolumn{3}{c|}{ 2004 } & \multicolumn{3}{|c|}{ 2005 } \\
\cline { 2 - 11 } & Valor & \%RO & \%RL & Valor & \%RO & \%RL & Valor & \%RO & \%RL \\
\hline USIMINAS & 29.329 & 1,16 & 0,34 & 11.862 & 0,24 & 0,10 & 60.466 & 1,27 & 0,46 \\
\hline COSIPA & 8.996 & & & 3.531 & & & N/d & & \\
\hline ALBRAS & 5.935 & & & 5.747 & & & N/d & & \\
\hline
\end{tabular}

\section{b) Comércio}

A empresa relacionada ao comércio não foi analisada, por não se enquadrar no ramo produtivo.

c) Serviços

REVISTA UNIARA, $n .^{0} 21 / 22,2008 / 2009$
Tabela 7. Investimentos relacionados à produção de geração de energia.

\begin{tabular}{|l|r|r|r|r|r|r|r|r|r|}
\hline \multicolumn{9}{|c|}{ Atividade: Geração de energia } \\
\hline \multirow{2}{*}{ Empresa } & \multicolumn{2}{|c|}{$\mathbf{2 0 0 3}$} & \multicolumn{2}{c|}{$\mathbf{2 0 0 4}$} & \multicolumn{3}{c|}{$\mathbf{2 0 0 5}$} & \\
\cline { 2 - 12 } & Valor & \%RO & \%RL & \multicolumn{1}{|c|}{ Valor } & \%RO & \%RL & Valor & \%RO & \%RL \\
\hline CATAQUAZES & 106.000 & & & 172.000 & & & 753.000 & & \\
\hline CESP SP S/A & N/D & & 5.737 .000 & & & 8.786 .000 & & \\
\hline CHESF CIA HID & 14.416 .000 & & & 5.395 .000 & & & N/D & & \\
\hline ELETRONORTE & 13.620 .000 & & & 14.949 .000 & & & N/D & & \\
\hline CG TEE & 1.471 .000 & & & 2.481 .000 & & & N/D & & \\
\hline COELCE ENER & N/D & & & 4.688 .000 & & & 8.235 .000 & & \\
\hline CPFL & N/D & & 56.229 .000 & & & 24.342 .000 & & \\
\hline ELETROSUL & 646.000 & & & 1.368 .000 & & & N/D & & \\
\hline ENERGIPE & N/D & & & 9.000 & & & 8.000 & & \\
\hline FURNAS & 11.903 .000 & & & 15.293 .000 & & & N/D & & \\
\hline LIGTH & N/D & & & 3.625 & & & 5.546 & & \\
\hline SAELPA & N/D & & & N/D & & & 127.000 & & \\
\hline
\end{tabular}

Fonte: próprio autor.

Deve-se ressalvar o número expressivo de demonstrações de empresas do setor hidrelétrico que, devido à privatização, ficaram ligadas a grandes grupos, que publicam suas demonstrações em conjunto.

Em 2005, 13 empresas publicaram o Balanço Social, contra 18 no ano de 2004 representando, respectivamente, $43 \%$ e $39 \%$ do total das publicações do período (tabela 4), ou seja, menos de 50\% do universo pesquisado, o que revela a falta de preocupação com a divulgação, pela maioria das empresas.

Dentro do grupo das empresas consideradas altamente poluidoras, as indústrias petrolíferas e siderúrgicas, os dados revelam que a Petrobrás, nos últimos anos, reduziu os investimentos relacionados com produção/operação da empresa (que figuram no item 4.1 tabela 1) de 2,00\% para 1,00\% e 0,90\% da sua receita líquida de 2003 para 2005, o que pode ser evidenciado, também, em relação ao resultado operacional (tabela 5), o que, em tese, pode revelar uma menor preocupação da empresa com os investimentos ambientais relacionados à produção.

Em relação às siderúrgicas, os dados revelam pouco investimento, pela relevância do tema na atual conjuntura (tabela 6).

Já os valores descritos na tabela 7 são inconsistentes para análise, uma vez que as empresas desse setor informaram gastos relativos aos programas de educação ambiental juntamente com outros eventos de responsabilidade social.

Diante dos valores extraídos acima, pode-se revelar que, no intervalo pesquisado, não é possível estabelecer uma relação entre os verdadeiros valores que as empresas aplicam na área ambiental, uma vez que a divulgação é extremamente inadequada para que o usuário externo os conheça.

Um estudo sobre as publicações... 


\section{Investimentos em programas ou projetos externos}

Os valores contidos no período delimitado não são relevantes para análise, uma vez que, das empresas pesquisadas, somente duas, em 2004, e quatro, em 2005 , divulgaram valores nesse campo.

\section{Considerações finais}

Em resposta à pergunta formulada, analisando o intervalo delimitado na pesquisa observa-se que, apesar de existirem modelos minimamente adequados para que as empresas revelem seus verdadeiros interesses em relação ao desenvolvimento sustentável, não se pode dizer que as mesmas estão ampliando seus investimentos relacionados à produção visando à sustentabilidade. Apesar de um campo específico dentro da demonstração conhecida como Balanço Social, percebe-se a carência em se classificar quais itens devem figurar nas linhas destinadas para esse fim.

Outro fato que deve ser considerado diz respeito ao que pode ser um efeito oriundo das aplicações em anos anteriores, uma vez que o investimento feito em determinado período não seria mais necessário no período seguinte, o que pode explicar uma redução gradativa nos investimentos.

Como crítica ao modelo utilizado pelo IBASE, o item 4.1 (tabela 1), investimentos relacionados à produção/operação da empresa, na atualidade e perto da dimensão que o tema ganhou nos últimos anos, sugere-se seu desmembramento com a inclusão de outros itens relevantes como, por exemplo, os valores dos ativos e passivos ambientais. Outros investimentos que a empresa está realizando devem encontrar espaço para divulgação, também ficando clara a distinção entre investimentos ou despesas que podem estar alocadas naquela rubrica.

A falta de informações revela, também, um outro espaço que precisa ser ocupado dentro das organizações, ou seja, o que está reservado à Contabilidade Ambiental. Esse tema tem permeado vários trabalhos realizados por pesquisadores competentes e muito se tem evoluído; entretanto, a sua implantação dentro das organizações ainda é lenta. Fato é que os valores gastos com a preservação do meio ambiente já são contabilizados, embora eles não estejam segregados nas Demonstrações Financeiras. Com a adoção da Contabilidade ambiental os valores poderão ser registrados adequadamente, dentro dos princípios fundamentais de contabilidade e, finalmente, encontrar demonstrações que convirjam para os usuários externos das informações prestadas pelas organizações.

\section{Referências bibliográficas:}

ASHLEY, P.A.; COUTINHO, R.B.G.; TOMEI, P.A. Responsabilidade social corporativa e cidadania empresarial: uma análise conceitual comparativa. ENCONTRO ANUAL DAASSOCIAÇÃO NACIONAL DOS PROGRAMAS DE PÓS-GRADUAÇÃO EM ADMINISTRAÇÃO, 24., 2000. Florianópolis. Anais... Florianópolis, 2000.

BELLO, C.V.V. Zeri: uma proposta para o desenvolvimento sustentável, com enfoque na qualidade ambiental voltada ao setor industrial, 1998. 117f. Dissertação (Mestrado)- Florianópolis, Universidade Federal de Santa Catarina, 1998

CAMARGO, A.L.B. Desenvolvimento sustentável: dimensões e desafios Campinas: Papirus, 2003.

\section{CONSELHO FEDERAL DE CONTABILIDADE. Normas Brasileiras de} Contabilidade - NBC T 15 Informações de natureza social e ambiental. Disponível em: <www.portaldecontabilidade.com.br/nbc/>. Acesso em: 24 jul. 2009.

INSTITUTO BRASILEIRO DE ANÁLISES SOCIAIS E ECONÔMICAS (IBASE). Balanço Social. Disponível em: <www.balancosocial.org.br>. Acesso em: 20 ago. 2006.

MILANI FILHO, M.A.F. Responsabilidade social e investimento social privado: entre o discurso e a evidenciação. R. Cont. Fin., USP, v.19, n.47, maio/agosto 2008. p.89-101.

RIBEIRO, M.S. Contabilidade ambiental. São Paulo: Atlas, 2005.

SILVA, B.A. Contabilidade e meio ambiente: considerações teóricas e práticas sobre o controle dos gastos ambientais. São Paulo:Annablume/Fapesp, 2003.

TINOCO, J.E.P. Balanço social: uma abordagem da transparência e da responsabilidade pública das organizações. São Paulo: Atlas, 2001.

ZANLUCA, J.C. Contabilidade ambiental, 2007 . Disponível em: <www.portaldecontabilidade.com.br>. 
Title:

\section{A STUDY ON THE PUBLISHING OF ENVIRONMENTAL \\ INVESTMENTS IN THE ENTERPRISE SECTOR USING THE \\ SOCIAL BALANCE.}

\section{Abstract:}

In recent years the interest of the society in knowing the true investments of the companies in social responsibility and environment has been frequent. One of these examples can be observed by knowing of the Business Charter for Sustainable Development of the International Chamber of Commerce (ICC), divulged in 1991, that suggests some actions that the companies must take in order to be prepared for the new reality originated from environment issues. Being thus, the concern with the environment, boasted in all the spheres of the society, gave space to two subjects of great repercussion in internal and external environments of the organizations: the social responsibility and the concern with the environment. In this context, the demonstration that can supply stakeholders with environment information is the social balance, that has as objective to demonstrate the result of the interaction of the company with the environment. Based on the above considerations, the question which we can make is: in spite of all the persistence of society, can we say that the companies have gradually increased their investments related to environment? This subject is justified by the fact that the companies have used the applications in environment and social responsibility for marketing purposes; however, the applied values and their true involvement adding this information to their financial demonstrations can only be identified by occasion of these publications. The objective of this work was to research the number of companies which had published information of social and environmental nature, in 2005 and 2006, by means of social balance, and afterwards, to verify the behavior of the environmental pointers which were divulged in the mentioned balances and were related to production. The present work was developed by means of documentary and descriptive research and was based on the published financial demonstrations in specific media. In reply to the research question, and analyzing the time interval delimited in the research, it is observed that, although minimum adequate models exist so that the companies disclose their true interests in relation to sustainable development, we cannot say that the companies are extending their investments related to production aiming at sustainability.

Keywords: Environment, Social Responsibility, Social Balance. 